\title{
Market Efficiency in the Financial Services Industry: Buyer Search Behaviour on an Electronic Commodity Market
}

by

Dennis Kundisch

April 2002

in: Electronic Markets, 13, 1, 2003, p.80-93 


\title{
Market Efficiency in the Financial Services Industry: Buyer Search Behaviour on an Electronic Commodity Market
}

by Dennis Kundisch

\begin{abstract}
:
Due to the immateriality of financial services and products they lend themselves handsomely for sale on the WWW. This may be one of the main reasons why the financial services industry has gained a cutting edge in the net with respect to other industries. Thus, at the beginning of the third millennium, the market for financial services is undergoing a fundamental shift since it is questionable whether the traditional approach of just selling financial commodity products in increasingly transparent and global markets will still be profitable in the future. Applying search cost theory, the gap of two formerly separately analysed search methods - sequential and simultaneous search - is closed in this article to contribute to the explanation of customer buying behaviour in an electronic commodity market such as the market for financial (commodity) products. The set-up of the model and the theoretical results are confronted with empirical evidence from German financial services market with respect to comparison shopping. Overall, the results suggest that issues like branding, trust, and retailer efforts to build consumer lock-in may become much more important in the future for financial services providers to successfully compete in the market.
\end{abstract}

\section{Keywords:}

Search Cost, Search Behaviour, Electronic Market, Financial Services Industry, Market Efficiency 


\section{Introduction}

In the last couple of years the financial services market has emerged as one of the most important electronic markets ${ }^{1}$ in the B2C segment. Due to the immateriality of financial services and products they lend themselves handsomely for sale on the WWW. This may be one of the main reasons why the financial services industry has gained a cutting edge in the net with respect to other industries. Underpinning this cutting edge, the popularity of finance related websites is striking. For instance in Germany in November 2000 already more than one third (roughly 4 Mio. persons) of all German Internet users surfing from home regularly accessed finance related websites (cf. Anonymous 2001a).

Thus, at the beginning of the third millennium, the market for financial services is undergoing a fundamental shift since it is questionable whether the traditional approach of just selling financial commodity products in increasingly transparent and global markets will still be profitable in the future. ${ }^{2}$ One of the most cited reasons why electronic markets are expected to be more efficient than conventional markets is a reduction in information asymmetries between a seller and a potential buyer due to lower search cost. ${ }^{3}$ Economic theory predicts that (high) consumer search cost will lead to prices above marginal cost in equilibrium (Stigler 1961; Diamond 1971). If electronic markets allow consumers to more easily determine retailers' prices and product offerings, these lower search cost will lead to lower prices for both homogeneous and differentiated goods (Bakos 1997). There are four dimensions of Internet market efficiency that can be distinguished (Smith et al. 2000):

- Price level: Are the prices charged on the Internet lower?

- Price elasticity: Are consumers more sensitive to small price changes on the Internet?

- Menu costs: Do retailers adjust their prices more finely and more frequently on the Internet?

- Price dispersion: Is there a smaller spread between the highest and lowest price on the Internet?

Early research suggests that electronic markets are more efficient than conventional markets with respect to price levels ${ }^{4}$, menu costs, and price elasticity. At the same time, several studies find significant price dispersion in Internet markets. This price dispersion may be explained by heterogeneity in retailer-specific factors such as branding, trust, other retailer efforts to build consumer lock-in, and various retailer price discrimination strategies (Smith et al. 2000).

For instance Brynjolfsson and Smith (2000) find that prices on the Internet for the commodity products books and CDs are $9-16$ per cent lower than prices in conventional outlets. They conclude that 'while there is lower friction in many dimensions of Internet competition, branding, awareness, and trust remain important sources of heterogeneity among Internet retailers.' Brown and Goolsbee (2000) seem to be the only ones to have analysed the efficiency effects of emerging electronic commodity markets with respect to financial services. They provide empirical evidence that Internet comparison shopping in the life insurance industry had reduced term life prices by 8 to 15 per cent from $1995-1997$. Interestingly, they also find that the initial introduction of Internet search sites is initially associated with an increase in price dispersion whereas while the share of people using the technology rises, dispersion falls.

Before getting into more detail, it is important to be very precise about the products in focus of this contribution. Products and services can usually be described by three different attributes (Kulkarni 2000):

- Search qualities are attributes that potential buyers can determine prior to purchase such as price and quality.

- Experience qualities are attributes determined only after or during consumption. 
- Credence qualities are intangible attributes that a potential buyer may be unable to determine even after purchase and consumption.

Hardly any financial service can be found that does not possess some characteristics of all of the above attributes. However, in most cases, either the search or the credence qualities prevail considering a specific financial service. Examples for financial services with search qualities include all kinds of (highly) standardized products, such as home mortgage loans, stock orders, time or fixed-term deposits, life insurance. Financial services possess credence qualities whenever it comes to consulting services, such as retirement planning or - in a broader context - financial planning. Generally, some sort of consulting service has to be called on before financial products are bought. Particularly in the domain of standardized financial services, dramatically shrinking margins could be observed in the last years. In the following a search cost model is presented that may be used to explain some of the observable tendencies in the financial services markets with respect to shrinking margins. The remainder of this contribution is organized as follows. After a literature review in the next section, the basic search cost model is developed and conclusions are drawn in light of declining search cost and new market entrants, respectively. Consequently, the assumptions and theoretical results are confronted with empirical evidence from the German financial services market leading to an extension of the basic model. Finally, some limitations of the analysis are discussed and the main findings are briefly summarized.

\section{Literature review}

Prior to the seminal paper from Stigler in 1961 on the economics of information, economic models assumed perfectly informed customers or implicitly a costless information process for both the supplier and for the potential consumer. In such a setting without capacity constraints on commodity markets, the standard economic Bertrand model suggests price will be driven down to marginal cost independent of the number of firms (Bertrand 1883). This market outcome is generally referred to as the Bertrand Paradox (Tirole 1988). In the context of traditional theory this setting includes the predictions that a given commodity is sold at the same price by all financial services providers (Law of the Single Price) and that differences in price just reflect differences in the quality of a product (Stiglitz 1989). Introducing a costly search process to this scenario yields the so-called Diamond Paradox, where firms paradoxically will set monopoly prices in equilibrium independent of the number of firms and consumers will not search (Diamond 1971). ${ }^{5}$ This shows impressively how sensitive the conclusions of the traditional paradigm are to its assumptions concerning information (Stiglitz 1989) ${ }^{6}$.

In contrast, Stigler (1961) (initially) takes the price dispersion as given and analyses the behaviour of an imperfectly informed consumer interested in buying a homogeneous product, i.e. the product is sufficiently described by its price and therefore just possesses search qualities. Based on this model, Stigler derives a number of interesting hypotheses suggesting that search activity is driven by both cost and benefit factors. ${ }^{7}$

- There is an inverse relationship between the optimal amount of search and the cost of search in terms of the consumer's opportunity cost of time, the cost to the individual of processing new market information, and other direct search related costs such as transportation.

- Either a greater dispersion of prices or a greater expenditure on the commodity will lead to more search. 
Based on and extending Stigler's model a wide range of research on consumer search behaviour has been conducted. ${ }^{8}$ Anderson (1999), Will (1997), Burdett and Coles (1995), Stahl (1989) and Salop and Stiglitz (1982) all deal with price dispersion as an equilibrium outcome that can be explained by the costly search of information. Davis and Holt (1996) test the conclusions of Diamond's Paradox and Bakos (1997) examines the role of buyer search costs in markets with differentiated product offerings. Steck and Will (1998) identify action consequences for suppliers in electronic markets due to changing consumer behaviour that is attributable to a change in search costs. Salop and Stiglitz (1977) address the problem of heterogeneity of consumer rationality in the context of a costly information gathering. One of the few works dealing with financial services and search costs include Calomiris (1995) who qualitatively uses search cost theory to explain above marginal cost pricing in the retail banking market and proposes a decline in margins with the introduction of new services such as home banking.

In the context of the financial services market, it is assumed in the following that a potential consumer already identified the product she likes - for instance by getting advice from a financial consultant or by self-consulting with tools provided on the Internet - and is now looking for the lowest price. Thus, along with Diamonds model, the search process to find a product she likes is excluded here. ${ }^{9}$

\section{Search Cost Model ${ }^{10}$}

\section{Overview}

Similar to searches in traditional markets, online searches can be carried out either sequentially or simultaneously. Surfing through different web financial services providers evaluating products and prices is a sequential search; a price search based on a price database is an example of a simultaneous search (Whinston et al. 1997). Ideally a search result of a simultaneous search looks like a table where all the relevant information is gathered, compressed, and structured and the consumer may directly decide to buy the least expensive product upon the search result by a single mouse click. As the Internet becomes more and more pervasive, search costs studies have recently experienced a renaissance. Search costs have been dropping dramatically since physical distances have become much less relevant in net markets. A number of reasons contribute to decreasing search costs (Bakos 1997, 1998; Steck and Will 1999):

- In traditional, regional markets often contained untraceable products for the customer. These products can now be found in the electronic market.

- New suppliers of already known products can be found. ${ }^{11}$

- The data provided by online financial services providers and intermediaries are generally accessible more quickly, richer in content, and more up-to-date.

Hence, more products can be found much faster compared to physical markets. The shift from a traditional market to an electronic market is not only complemented by a sharp drop in search costs, but also a trend of declining search costs in electronic markets is observable. 
- The telecommunication markets in many countries have become more liberalized (e.g. in the European Union) resulting in decreasing prices. Moreover there is a high competition for online users among the Internet Service Providers leading to declining access fees ${ }^{12}$ (see Figure 1).

- Prices for computers and processing power, respectively, have fallen dramatically in the last decades.

- Fast and dynamically emerging Internet-based technologies facilitate the decrease of search costs. On the one hand search engines, either generic (like Google), hierarchical directories (like Yahoo!), or domain specific tools (like PlanetHome for the mortgage loan market) and on the other hand intelligent agents keep lowering buyers' search cost. $^{13}$

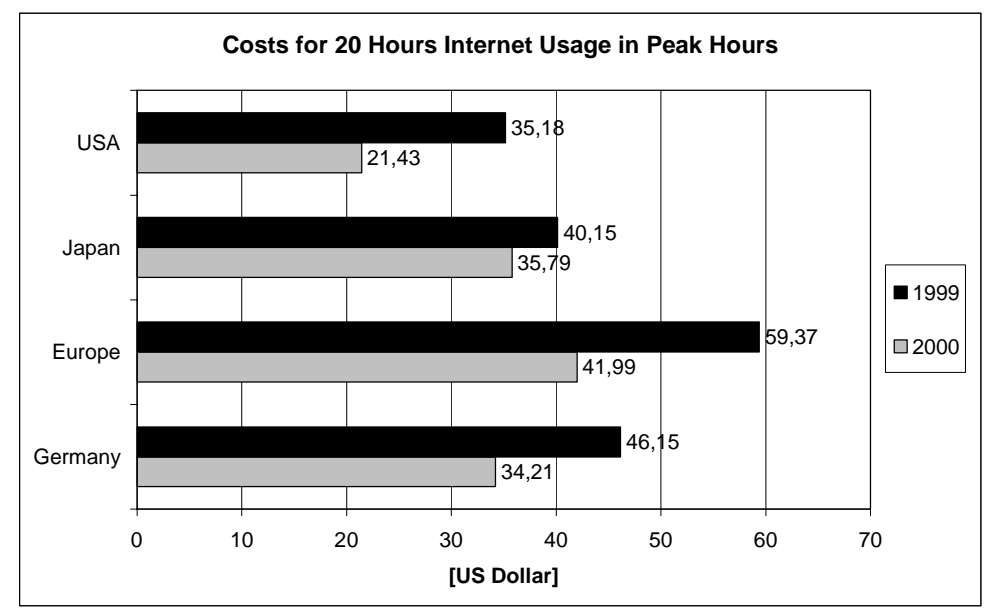

Figure 1. Decline in Costs of Internet Usage; (own graph, figures are taken from (Anonymous 2001b).

According to Drucker (1999) the financial services industry's products have become commodities during the last three decades. Thus, a simple search cost model shall suffice here to analyse the consumer behaviour and its implications on market outcomes in the financial services market. Shy (1997) examined the strategy of consumers searching sequentially in such a commodity market and determined the expected number of financial services provider visits until a customer will buy a product. Here, while allowing for more flexibility, a model is developed building upon and extending the work of Shy (1997) by combining the sequential search model with a simultaneous search model ${ }^{14}$ allowing for a full examination of consumer search behaviour in an (electronic) commodity market.

In the following sections, it will be illustrated that the decision for a specific search method has a great impact on which product will be found and purchased. As this is certainly interesting information for financial services providers, conclusions will be drawn for both the consumers and the suppliers. Also the impacts of decreasing search costs and additional suppliers in the market - trends that have been observable on the Internet - on the search behaviour will be identified. 


\section{Assumptions}

(AP) Product

The offered product is homogeneous and sufficiently described by its price.

(AM) Market

In an electronic market there are $n$ financial services providers selling a homogeneous product. With no loss of generality $^{15}$, it is assumed that the price charged by each financial services provider of type $i, i=c, c+1, \ldots, e$ with $0 \leq c \leq e<\infty$ and $n=(e-c+1)$, is $p_{i}=i$. That is for example a financial services provider of type 3 charges $p_{3}=3$. Note that for the case when $c=0$ there is also a financial services provider of type 0 that charges $p_{0}=0$. Prices are exogenously given, and financial services providers do not change prices. ${ }^{16}$

\section{(AC) Consumer}

The risk neutral consumer knows the distribution of the prices but does not know which price is charged by a particular financial services provider. ${ }^{17}$ That is, the consumer knows that in the market there are $n$ prices in the range of $p=c, c+1, \ldots, e$ but she does not know the exact price offered by each individual financial services provider. The consumer can decide to search simultaneously or sequentially. If she decides to search simultaneously she bears a constant search cost (including possible fees from the search agent) of $\alpha_{s i}>0$ per search. If she decides to search sequentially she bears a constant search cost of $\alpha_{s e}>0$ for each time she visits a financial services provider.

(AD) Decision Rule

The consumer will opt for the search method with the lowest expected total cost, that is the expected costs for the search and the expected product price.

\section{(AE) New Market Entrants}

New market entrants can either charge a lower price than financial services provider $c$ or a higher price than financial services provider $e$.

The distribution of the prices can be graphically illustrated in Figure 2. In this example the lowest price is $p_{c}=0$. 


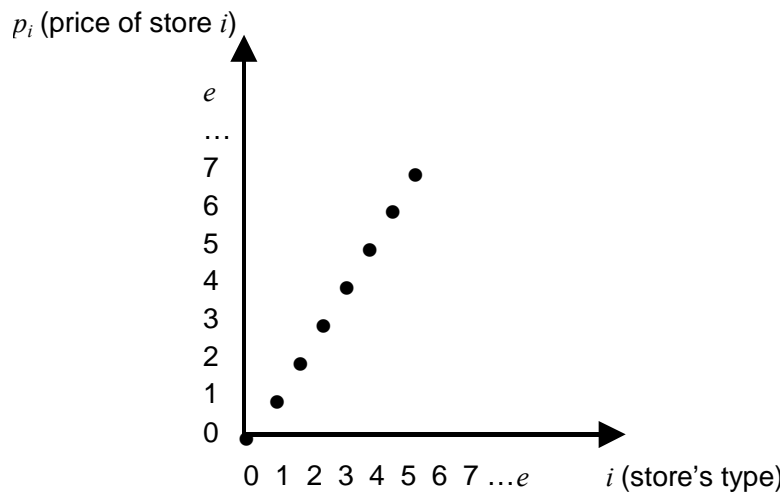

Figure 2. Supplier prices and financial services provider distribution, (Shy 1997), modified.

Zero prices are a phenomenon that can often be observed on electronic markets concerning digital products. Some rational reasons for this pricing behaviour are listed below.

- First, a supplier can decide to generate its revenues from online advertisements (paid banners or paid links) rather than charging the consumers a price for their products. ${ }^{18}$

- Second, a supplier aims to utilize the lock-in effect, hence it is providing its digital product for free. Besides domain independent products such as the freely distributed Acrobat Reader, one example in the domain of financial services is the free distribution of HBCI home banking software by German Landesbank Baden-Württemberg for a limited time.

- Third, in order to become well known a new supplier in the market might provide its digital product for a limited period for free.

- Fourth and in the context of financial services most important, marginal cost of digital products approach zero, excluding any copyrights duties. Hence, suppliers may charge some kind of subscription or other fixed fee to cover their high fix costs but nothing for the product or service.

To summarize, the consumer knows the distribution of the prices and will calculate the total expected cost before starting to search. She will opt for that search method that leads to the lowest possible total cost. This scenario can be visualized in Figure 3.

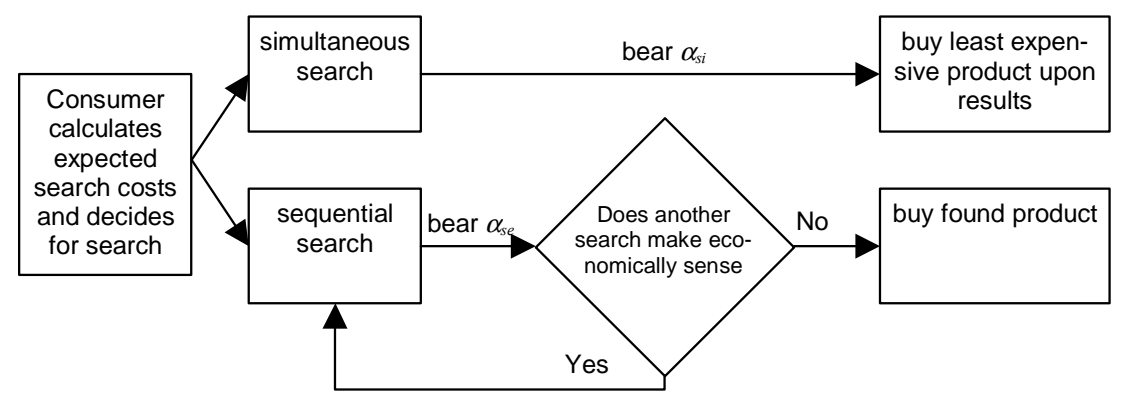

Figure 3. Consumer Search for Homogeneous Products. 
In a first step the sequential search will be examined in more detail. In a second step the expected costs for a simultaneous search will be the centre of interest. Consequently both approaches will be combined.

\section{Sequential Search}

Suppose a consumer has decided to search sequentially, how can she determine when to stop the search process with a price offer $p_{i}$ in hand? In a sequential search the consumer has a strict sunk cost perspective. This means a consumer will never look back and stop her search because of the loss caused by several searches in the past. Each time she visits a financial services provider and gets the price information $p_{i}$, she calculates the expected price reduction from visiting one additional financial services provider and compares this with her search cost $\alpha_{s e}$. Since the consumer by assumption knows the prices (Assumption (AC)) and each price is realized with probability $1 / n^{19}$, the expected reduction epr is

$$
\operatorname{epr}\left(p_{i}\right)=\frac{\left(p_{i}-p_{c}\right) \cdot\left(\left(p_{i}-p_{c}\right)+1\right)}{2 \cdot n} .
$$

If the consumer concludes the search by buying the product, then her 'loss' is $p_{i}$. In contrast, if she rejects the price offer and searches one more time, then the expected loss is the sum of an additional search cost $\alpha_{s e}$, plus the current price offer, minus her expected gain from searching one more time. Formally, the consumer with an offer $p_{i}$ in hand minimizes

$$
L\left(p_{i}\right)=\left\{\begin{array}{ll}
p_{i} & \text { if she buys and pays } p_{i} \\
\alpha_{s e}+p_{i}-\operatorname{epr}\left(p_{i}\right) & \text { if she searches one more time }
\end{array} .\right.
$$

Thus, a consumer continues searching if and only if the price in hand $p_{i}$ satisfies $\operatorname{epr}\left(p_{i}\right)>\alpha_{\text {se }}$. This is called a reservation-price strategy (cf. McCall 1965) ${ }^{20}$.

The reservation price $\bar{p}$ represents that price when the consumer is indifferent between affording another search or just buying the product with the price offer $p_{i}$ in hand. Formally, solving the equation $\alpha_{s e}=e \operatorname{er}\left(p_{i}\right)$ for $p_{i}$ yields the reservation price

$$
\bar{p}=p_{c}+\frac{-1+\sqrt{1+8 \cdot \alpha_{s e} \cdot n}}{2}
$$

Proposition 1: In a sequential search market both new less expensive suppliers and declining search costs will increasingly drive more expensive established suppliers out of the market.

In most cases, new less expensive suppliers $\left(p<p_{c}\right)$ entering the market and declining search costs will cause a decrease in the reservation price ${ }^{21}$, making a consumer reject more offered products before she is willing to buy it. New more expensive suppliers will cause an increase in the reservation price. If the search costs become negligible, thus $\alpha_{s e}=0$, the consumer will search till she finds $p_{c}$. Financial services provider have to acknowledge the fact that due to the reservation price strategy a buyer that once decided not to buy at a found financial services provider will never buy there 
during this search process, even if she comes back to this financial services provider coincidentally. ${ }^{22}$ Interestingly, if a financial services provider knew the buyer's search cost (and like the buyer the price distribution ${ }^{23}$ ) it could guarantee the customer - if appropriate - that another search makes economically no sense.

Example 1: Suppose the consumer wants to perform a stock order on the Internet and knows that there are 25 suppliers offering this service between $\$ 30$ and $\$ 54\left(p_{c}=30, p_{e}=54\right)$. A search agent is not available hence the consumer may only search sequentially. She calculates her reservation prices for several scenarios that are presented in Table 1 .

Table 1. Reservation Prices for Sequential Search.

\begin{tabular}{llll}
\hline \multirow{4}{*}{ Search costs } & \# of Suppliers (Price range) & \\
& $25(\$ 30-\$ 54)$ & $30(\$ 25-\$ 54)$ & $30(\$ 30-\$ 59)$ \\
& Initial situation & 5 new cheaper suppliers & $\begin{array}{l}5 \text { new more expensive } \\
\text { suppliers }\end{array}$ \\
{$[\$]$} & {$[\$]$} & {$[\$]$} & {$[\$]$} \\
\hline 10 & 51.90 & 49.00 & 54.00 \\
5 & 45.30 & 41.80 & 46.80 \\
2 & 39.50 & 35.50 & 40.50 \\
1 & 36.60 & 32.30 & 37.30 \\
\hline
\end{tabular}

To determine the total expected cost of a sequential search, the chronological order of how costs are incurred was evaluated. The consumer visits the first financial services provider $i$, looks at the price $p_{i}$, compares the price with her reservation price and decides either to buy the product, thus incurring total cost of one search and product price $p_{i}$ or to go on searching. If she goes on searching, in the next shop it is just the same except for the total cost consisting now of two searches and the 'new' product price. Formally the consumer will calculate the expected number of financial services provider visits esv to find an appropriate price times the search cost $\alpha_{\text {se }}$ and the expected product price epp.

If the price of a found product is below the customer's reservation price, she will buy it without any further searches. Obviously, when the reservation price is greater than the highest price in the market ${ }^{24}$ the consumer will always buy the first found product right away. Hence the expected product price is given by $\left(p_{e}+p_{c}\right) / 2$. If the reservation price is below the most expensive product in the market, the consumer will expect to pay $\left(\bar{p}+p_{c}\right) / 2$ since she will only buy a found product that costs at most the reservation price.

$$
\text { epp }= \begin{cases}\frac{\bar{p}+p_{c}}{2} & \text { if } \bar{p} \leq p_{e} \\ \frac{p_{e}+p_{c}}{2} & \text { if } \bar{p}>p_{e}\end{cases}
$$

The total expected cost of the search process that concludes in buying a product not only comprises the expected product price but also the expected number of financial services provider visits times the sequential search cost. Denoting the probability that a consumer will not buy at a found financial services provider by $\sigma$, the expected number of store visits can be calculated. Bearing in mind that according to the reservation price strategy, the consumer will not buy at a financial services provider $i$ where $p_{i}>\bar{p}$. Thus, the probability that she will buy at a single financial services provider is $\left(\bar{p}-p_{c}+1\right) / n$ since she will reject all price offers greater than her reservation price. 
Obviously, the probability that will she buy in the first store is $(1-\sigma)$. Accordingly, the probability that she will not buy in the first, but in the second store is $\sigma(1-\sigma)$ and that she will not buy during her first two store visits but in the third visit is given by $\sigma^{2}(1-\sigma)$. Finally, the probability that a consumer will buy at the $t$ 's financial services provider visit is given by $\sigma^{t-1}(1-\sigma)$. To find the number of financial services providers to be visited before buying the product, the probabilities of buying at each given visit times the visit's number have to be summed (cf. Shy 1997). Hence the expected number of financial services provider visits $e s v$ is given by ${ }^{25}$

$$
\begin{aligned}
e s v & =\sum_{t=1}^{\infty} \sigma^{t-1}(1-\sigma) t \\
& =\frac{1}{1-\sigma} \\
& =\left\{\begin{array}{cc}
\frac{2 \cdot n}{1+\sqrt{1+8 \cdot n \cdot \alpha_{s e}}} & \text { if } \alpha_{s e}<\frac{n-1}{2} \\
1 & \text { if } \alpha_{s e} \geq \frac{n-1}{2}
\end{array}\right.
\end{aligned}
$$

Combining Equation (4) and Equation (5) and substituting $\bar{p}$ using Equation (3) yields the expected total costs $T C_{s e}$.

$$
\begin{aligned}
& T C_{s e}=\left(\begin{array}{c}
\text { expected } \# \text { of searches } \\
\cdot \text { search cost per search }
\end{array}\right)+(\text { expected product price }) \\
& =\left\{\begin{array}{cll}
\frac{2 \cdot n}{1+\sqrt{1+8 \cdot n \cdot \alpha_{s e}}} \cdot \alpha_{s e} & +p_{c}+\frac{-1+\sqrt{1+8 \cdot n \cdot \alpha_{s e}}}{4} & \text { if } \alpha_{s e}<\frac{n-1}{2} \\
1 \cdot \alpha_{s e} & +\frac{p_{c}+p_{e}}{2} & \text { if } \alpha_{s e} \geq \frac{n-1}{2}
\end{array}\right.
\end{aligned}
$$

Equation (6) can be simplified as follows:

$$
T C_{s e}= \begin{cases}p_{c}+\frac{-1+\sqrt{1+8 \cdot n \cdot \alpha_{s e}}}{2} & \text { if } \alpha_{s e}<\frac{n-1}{2} \\ \alpha_{s e}+\frac{p_{c}+p_{e}}{2} & \text { if } \alpha_{s e} \geq \frac{n-1}{2}\end{cases}
$$

Proposition 2: In a sequential search market the total expected cost associated with searching and buying a product equals the reservation price of the customer.

Equation (7) presents a very interesting outcome. Initially, the reservation price was the basis for the customer to decide whether she should search once again or buy the product in hand. Now it has been shown that the reservation price implicitly also represents the total expected cost for finding and buying a commodity in a sequential search market.

The conclusions that can be derived from Equation (7) are generally the same as the ones for Equation (3). A decrease in the consumer search costs decreases the expected total cost. Decreasing search costs favour the cheaper suppliers since the consumer will search more often. If the search costs become negligible, the expected total cost would just be $p_{c}$ because the consumer searches until she finds the lowest price without bearing any search costs. In such a market all other suppliers would not sell a product anymore. An increase in the number of financial services providers in the market would decrease the expected total cost if cheaper suppliers enter the market and increase the expected total cost 
if more expensive suppliers enter the market. A market entry in such a market makes sense if and only if $\alpha_{s e} \geq(n-1) / 2$.

Otherwise no revenues can be expected since already slightly cheaper suppliers are not able to sell a product. $^{26}$

Example 2: The consumer in Example 1 wants to calculate her total expected cost for finding an appropriate supplier and performing the stock order on the Internet. Since she already calculated her reservation prices for various scenarios (see Table 1) she implicitly has already determined her total expected cost. A new calculation is not necessary.

\section{Simultaneous Search}

Determining the results of a simultaneous search is much easier compared to the sequential approach. Assume that the information broker or search agent has full information on suppliers, their products and prices, hence the result of the simultaneous search will be financial services provider $c$ offering the product at price $p_{c}$. So, - and this is quite noteworthy - the consumer can be sure to get the best offer, if she chooses to search with the information broker or search agent. To get the total cost incurred by a simultaneous search the sum of the least expensive offer and the search $\operatorname{cost} \alpha_{s i}$ has to be calculated.

$$
T C_{s i}=\alpha_{s i}+p_{c}
$$

Proposition 3: In a simultaneous search market the least expensive supplier will always be found and only this supplier will generate revenues.

A decrease in search costs reduces the total cost for the buyer but does not affect the found supplier. An increase in the number of financial services providers in the market has only an impact on total cost if cheaper suppliers enter the market. In a market where buyers just search simultaneously only the least expensive supplier will survive. It makes no sense economically to enter such a market with more expensive products.

Example 3: Suppose the consumer in Example 1 discovers that there is a search agent available that allows searching simultaneously for the best broker on the Internet. For the total expected cost she calculates the following for the different scenarios (see Table 2). 
Table 2. Total Expected Cost for Simultaneous Search.

\begin{tabular}{llll}
\hline \multicolumn{5}{l}{ \# of Suppliers (Price range) } \\
Search costs & $\begin{array}{l}25(\$ 30-\$ 54) \\
\text { Initial situation }\end{array}$ & $30(\$ 25-\$ 54)$ & $30(\$ 30-\$ 59)$ \\
& & 5 new cheaper suppliers & $\begin{array}{l}5 \text { new more expensive } \\
\text { suppliers }\end{array}$ \\
{$[\$]$} & {$[\$]$} & {$[\$]$} & {$[\$]$} \\
\hline 10 & 40.00 & 35.00 & 40.00 \\
5 & 35.00 & 30.00 & 35.00 \\
2 & 32.00 & 27.00 & 32.00 \\
1 & 31.00 & 26.00 & 31.00 \\
\hline
\end{tabular}

\section{Combined Approach}

With both approaches in hand, one can now determine whether the consumer will decide to search simultaneously or sequentially. She simply calculates the expected total costs of the sequential search and compares these with the total costs of the simultaneous search ${ }^{27}$. She will use an information broker or search agent if and only if the total cost of the simultaneous search is lower than the expected total cost of purchasing a product using a sequential search.

$$
\begin{aligned}
& T C_{s i}<T C_{s e} \\
& p_{c}+\alpha_{s i}< \begin{cases}p_{c}+\frac{-1+\sqrt{1+8 \cdot n \cdot \alpha_{s e}}}{2} & \text { if } \alpha_{s e}<\frac{n-1}{2} \\
\alpha_{s e}+\frac{p_{c}+p_{e}}{2} & \text { if } \alpha_{s e} \geq \frac{n-1}{2}\end{cases}
\end{aligned}
$$

Proposition 4: A consumer will search sequentially if and only if her reservation price is lower than the least expensive product price plus the charge for a simultaneous search.

Unless information about the differences in the search costs $\alpha_{s i}$ and $\alpha_{s e}$ is available a particular search method cannot be generally recommended. Obviously, if the search costs become negligible, the consumer is indifferent between the two search methods and will find the least expensive offer without bearing any search costs. An increase in the number of cheaper financial services providers in the market would decrease both the total expected cost for both the sequential and the simultaneous search. A financial services provider might be able to charge more than $p_{c}$ for its product only if the sequential search generally is the superior choice.

Example 4: Suppose the consumer of the Examples 1 to 3 faces search costs of $\$ 10$ for a simultaneous search and $\$ 2$ for each sequential search and still wants to perform the stock order. The results are gathered in Table 3. While the sequential search is the better choice in the initial situation, this changes with 5 new - either less or more expensive suppliers. 
Table 3. Combined Approach - Consumer's Decision.

\begin{tabular}{|c|c|c|c|}
\hline \multirow[b]{2}{*}{ Search Costs } & \multicolumn{3}{|c|}{ \# of Suppliers (Price range) } \\
\hline & $\begin{array}{l}25(\$ 30-\$ 54) \\
\text { Initial situation } \\
{[\$]}\end{array}$ & $\begin{array}{l}30(\$ 25-\$ 54) \\
5 \text { new cheaper } \\
\text { suppliers } \\
{[\$]}\end{array}$ & $\begin{array}{l}30(\$ 30-\$ 59) \\
5 \text { new more expensive } \\
\text { suppliers } \\
{[\$]}\end{array}$ \\
\hline $\begin{array}{l}\text { Simultaneous } \\
\text { Search Cost: } \$ 10\end{array}$ & 40.00 & 35.00 & 40.00 \\
\hline $\begin{array}{l}\text { Sequential } \\
\text { Search Cost: } \$ 2\end{array}$ & 39.50 & 35.47 & 40.47 \\
\hline $\begin{array}{l}\text { Consumer } \\
\text { Decision }\end{array}$ & Search sequentially & Search simultaneously & Search simultaneously \\
\hline
\end{tabular}

Search cost on the Internet for both methods will often be approximately the same since most search agents do not charge an extra search fee and the time it needs to search with a search agent is pretty similar to the time it needs to browse the online presence of a financial services provider. Hence on the Internet $\alpha_{\mathrm{si}} \approx \alpha_{\mathrm{se}}$ will hold in many circumstances. This leads to a general preference for the simultaneous search because the reservation price is always greater or equal to $p_{c}$.

Proposition 5: In a market with equal (positive) costs for both search methods, the buyers will search simultaneously to discover the least expensive offer with its supplier being the only one to survive in the market.

Apparently, on the Internet, there is a strong pressure on margins since the search method of choice generally will be the simultaneous method yielding the least expensive supplier in the market. This finding shall be challenged with empirical evidence with respect to comparison shopping the form the German financial services market in the following section.

\section{Simultaneous Search in the German Financial Services Market ${ }^{28}$}

Fast evolving search technologies can be observed on the Internet, allowing customers to compare financial (commodity) products increasingly fast and conveniently. In the last sections, a simple search cost model was used to deduce implications for both customers and suppliers in an electronic commodity market.

With respect to a number of product categories - namely broking, current account, real estate financing (mortgages), fixed term deposits, loans, automobile third party insurance, private health insurance, and general third party liability insurance - an empirical study was conducted between November 2000 and January 2001 to assess the status quo of opportunities to compare highly standardized products in the German financial services market.

Across all comparison suppliers it became evident, that a customer already has to have a good knowledge about her needs and preferences. Accordingly she has to have a good knowledge about the financial service she is looking for in order to satisfy her needs ${ }^{29}$ due to the fact that all analysed comparisons are based on a specific financial service in contrast to specific needs of potential customers. Hence, with regard to comparison shopping there is still a productcentric view instead of a customer-centric and needs-centric, respectively, view observable in the market. For this kind 
of well-informed customers, the offered comparison services are generally powerful and offer valuable opportunities to save substantial amounts of money while optimising their private financial dispositions. The service comparisons and information provided along with the comparison are of particular interest and usefulness if the product or service is a highly standardized commodity (hence a homogeneous product as modelled above) that may be compared just by comparing the price.

Interestingly, the study revealed that there may be substantial differences in the result sets of suppliers of comparisons, i.e. the top offer based on the price for a specific service varied substantially. ${ }^{30}$ Thus, consulting several suppliers of comparisons before purchasing a financial service or product may be advisable. Some differences in the result sets with respect to the yielded least expensive supplier and the number of in the comparison included suppliers are summarized in Table 4. Astonishingly, different search agents yielded in some cases the same least expensive product supplier, however, with a different price for the same financial service.

Table 4. Result Range and Number of Included Suppliers ${ }^{31}$.

\begin{tabular}{lll}
\hline Product & Range of Least Expensive Offers & \# of Suppliers Included \\
\hline Mortgage Lending & $5,51 \%-5,57 \%$ & $74-220$ \\
Fixed term deposits & $4,30 \%-4,60 \%$ & $24-49$ \\
Auto insurance & $1.078 \mathrm{DM}-1269 \mathrm{DM}$ & $27-100$ \\
\hline
\end{tabular}

To recap, the study suggests that the transparency on the financial services market has increased dramatically with the new and evolving means of communication, however, there is still a long way to go until the full transparency of the market $^{32}$ is reached.

One of the implicit assumptions of the above presented model is that the search agent providing the means to perform a simultaneous search has a complete market overview, i.e. it will include all suppliers in the market in its comparison and will yield the least expensive supplier in the market as the result. However, as discussed above, empirical evidence with respect to the German financial services market suggests that there is no search engine in the market that provides a complete market overview. Therefore, the basic search cost model will be extended to account for this condition in the following.

\section{Extension of the Basic Search Cost Model}

In light of these empirical findings, obviously, the former simultaneous search problem and method exhibits sequential characteristics. If a consumer cannot be sure to get the least expensive product as a result of the simultaneous search, she will have to calculate just like in the sequential case whether another search makes economically sense or not. Thus, Figure 3 has to be modified to illustrate the new decision problem (see Figure 4). 


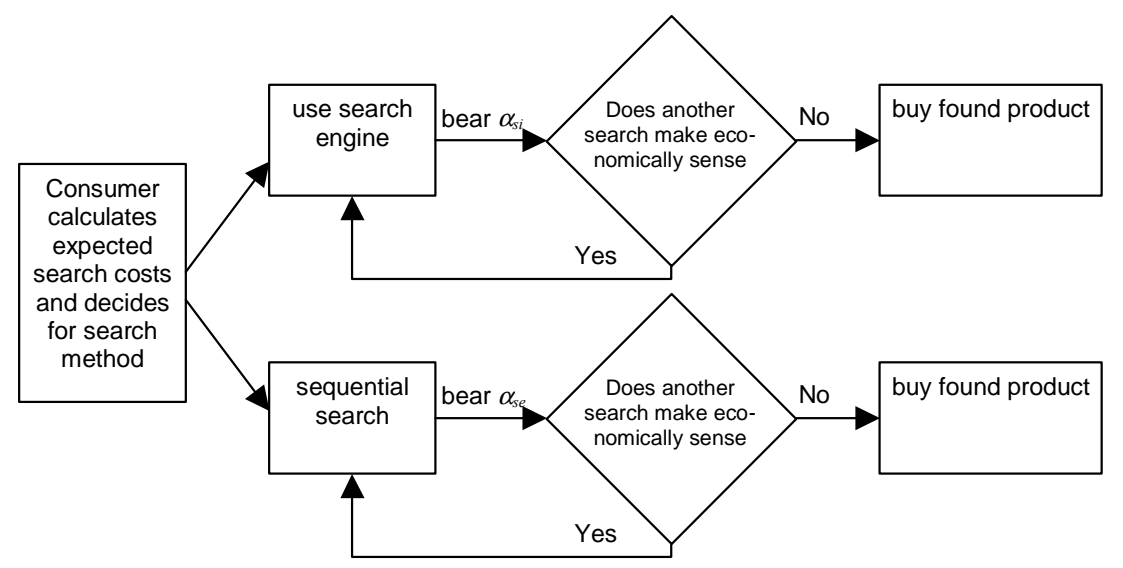

Figure 4. Consumer Search for Homogeneous Products Revisited.

In a very simple setting it can be shown that the simultaneous/sequential search method will still be preferred over the pure sequential search by the consumer.

\section{(AS) Search Agent}

Let $m$ denote the number of search agents in the market. Each of the $m \leq n / 2$ search agents is able to close exclusive contracts with at least 2 of the $n$ product suppliers. ${ }^{33}$ Furthermore, search agent $j=c, c+1, \ldots$ yields $p_{j}=j$ as the least expensive offer.

Figure 5 illustrates this new setting (analogously to Figure 2). Obviously the division of the prices in the range between $p_{c}+m \ldots p_{e}$ between the $m$ search agents is irrelevant for the decision problem in this scenario.

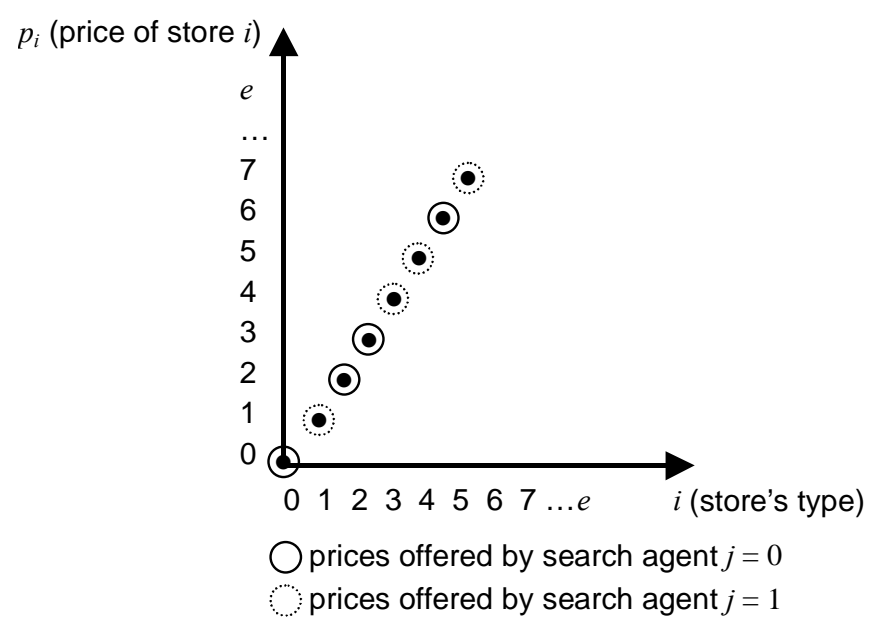

Figure 5. Supplier Prices, Financial services provider Distribution, and Search Agents. 
Total expected cost of the simultaneous/sequential search $T C_{s i s e}$ are then given by ${ }^{34}$

$$
T C_{s i / s e}=\left\{\begin{array}{ll}
p_{c}+\frac{-1+\sqrt{1+8 \cdot m \cdot \alpha_{s i}}}{2} & \text { if } \alpha_{s i}<\frac{m-1}{2} \\
\alpha_{s i}+\frac{p_{c}+p_{c+m}}{2} & \text { if } \alpha_{s i} \geq \frac{m-1}{2}
\end{array} .\right.
$$

Apparently, the preference for the simultaneous/sequential search method will hold in the case where search costs for both methods are the same (see Equation (11)). The special case where $m=1$ represents the already above discussed scenario (compare Equation (9)).

$$
\begin{array}{ll}
T C_{\text {si } / s e}>T C_{\text {se }} \quad \text { for } \forall m, n \\
\text { s.t. } \quad \alpha_{s i}=\alpha_{s e}
\end{array}
$$

Waiving the assumption of exclusive contracts in assumption (AS) makes the decision process much more complicated. Sampling from the assumed distribution in assumption (AM) generates a mathematically unhandy distribution.

Moreover in that scenario a general preference for one of the search methods cannot be shown.

After having extended the basic model, in the following some fundamental limitations of the analysis will be discussed in the following section.

\section{Limitations of the Analysis}

In general a search agent will have an information advantage compared to a consumer. Rothschild (1975) has shown that in many cases the qualitative characteristics of optimal search strategies with known distribution of prices are equal to those where the customer at first knows little or nothing about the distribution of prices but learns about the prices during her search.

The assumed risk neutrality of the consumer will often not hold true. Many people prefer a certain result (here: the simultaneous search in the basic model) to an uncertain event (here: the sequential search), hence they are risk averse. The model can be easily adjusted to take also into account the consumer attitude towards risk. Given the assumption that consumers are risk adverse, they will favour the simultaneous search even more.

It was assumed that search cost are either positive or zero. This need not hold true for all Internet surfers. Many people enjoy surfing and browsing the WWW looking for good deals or just for pleasure. Hence, searching the Internet could provide a customer with utility that may outweigh opportunity cost of time and online fees.

Even when buying commodity products like simple financial services, price is often not the only important factor that influences the buyer's decision. For example reliability, security and reputation of the financial services provider are probably also relevant factors that customers take into account. ${ }^{35}$ Also, price was taken to be a concrete attribute, however, research suggests that price perceptions are malleable. These behavioural and psychological aspects of price have not been addressed. ${ }^{36}$

These limitations of the analysis conclude the main body of the contribution. In the following, the main findings are briefly summarized. 


\section{Concluding Remarks}

The customer decision process for using either a sequential or a simultaneous search method in a commodity market has been examined. In the context of a sequential search, the outcomes reveal that the reservation price is not only the price where a consumer is indifferent between searching another time and buying the product in hand. It represents also the total expected cost associated with a search process and concluding the search in buying the product. If financial services providers knew the distribution of the prices in the market and the reservation price of a consumer, they could provide - if appropriate - the consumer with a guarantee that another search does not make sense economically.

It has been shown that both approaches to examining buyer search behaviour in (electronic) commodity markets can be comfortably combined. In the absence of special search charges by search agents, a strong preference for the simultaneous search method could be shown. In such a setting, a strong pressure on the prices in the commodity market should be observable since the simultaneous search yields always the least expensive supplier. Hence, a decision for a market entry will only be economically sound when the entrant is able to offer the homogeneous product less expensive. Kulkarni (2000) comes to the conclusion '.... a firm's informational advantage is generally likely to diminish in the long run in view of the recent advances in IT: This is because IT has greatly reduced the costs of disseminating and acquiring information.' The analysis here also reveals that it is highly questionable whether competing on price will be a sustainable business model in electronic commodity markets in the future. New strategies - like building customer trust relationships or differentiate by individualized services and products - may have to be found by financial services providers to successfully compete in such a transparent electronic marketplace.

\section{References}

ANDERSON, S., RENAULT, R., 1999, Pricing, Product Diversity, and Search Costs: A Bertrand-ChamberlainDiamond Model. The Rand Journal of Economics, 30, 719-735.

ANONYMOUS, 2001a, Consors \& Co. im Netz gefragt, http://www.ecin.de/news/ 2001/01/12/01403/index.html

ANONYMOUS, 2001b, Monitoring Informationswirtschaft, 3. Faktenbericht 2001 (Band I), Chartbericht zum 3. Faktenbericht 2001 (Band II), im Auftrag des Bundesministerium für Wirtschaft und Technology, Eine Sekundärstudie von NFO Infratest (Germany) München, August 2001 01.16.20302.020.

AVERY, R.J., 1996, Determinants of Search for Nondurable Goods: An Empirical Assessment of the Economics of Information Theory. The Journal of Consumer Affairs, 30, 390-420.

BAKOS, Y., 1991, A Strategic Analysis of Electronic Marketplaces. MIS Quarterly, 15, 295-310.

BAKOS, Y., 1997, Reducing Buyer Search Costs - Implications for Electronic Marketplaces. Management Science, 43, 1676-1692.

BAKOS, Y., 1998, The Emerging Role of Electronic Marketplaces on the Internet. Communications of the ACM, 41, $35-42$.

BEATTY, S.E., SMITH, S.M., 1987, External Search Effort: An Investigation Across Several Product Categories. Journal of Consumer Research, 14, 83-95.

BERTRAND, J.L.F., 1883, Théorie mathématique de la richesse social par Léon Walras: Recherches sur les principes mathématiques de la théorie des richesse par Augustin Cournot. Journal des savants, 67, 499-508.

BROWN, J., GOOLSBEE, A., 2000, Does the Internet Make Markets More Competitive? Evidence form the Life Insurance industry. National Bureau of Economic Research Working Paper No. 7996. 
BRYNJOLFSSON, E., SMITH, M., 2000, Frictionless Commerce? A comparison of Internet and Conventional Retailers. Management Science, 46, 563-585.

BUHL, H.U., KUNDISCH, D., STECK, W., LEINFELDER, A., 2001, IT-Enabled Sophistication Banking. In: WERTHNER, H., BICHLER, M., eds. Lectures in E-Commerce, Wien, Springer, 27-46.

BURDETT, K., COLES, M., 1995, Steady State Price Distributions in a Noisy Search Equilibrium. Journal of Economic Theory, 72, 1-32.

CALOMIRIS, C.W., 1995, Pricing margins: Competition is the driver. Journal of Retail Banking Services, 17, 59-62.

DAVIS, D., HOLT, C., 1996, Consumer Search Cost and Market Performance. Economic Inquiry, 34, $133-151$.

DEGROOT, M.H., 1970, Optimal Statistical Decisions. New York, McGraw-Hill.

DIAMOND, P.A., 1971, A Model of Price Adjustment. Journal of Economic Theory, 3, 156-168.

DIAMOND, P.A., 1989, Search Theory. In: EATWELL, J., MILGATE, M., NEWMAN, P., eds. The New Palgrave: allocation, information and markets. London, Macmillan Press Limited, 271-286.

DRUCKER, P., 1999, Drucker on financial services: Innovate or die. The Economist, September 25 ${ }^{\text {th }}: 27-34$.

FRANK, M., KUNDISCH, D., SCHELL, A ., 2000, Elektronischer Vertrieb von Dienstleistungen: Der optimale Serverstandort als Warehouse Location Problem. In: BODENDORF, F., GRAUER, M., eds. Verbundtagung Wirtschaftsinformatik 2000, Aachen, Shaker, 208-222.

FREY, M., 2000, Global-E verknüpft Märkte und Kunden. Information Management \& Consulting, 15, 79-81

KOERNER, V., ZIMMERMANN, H.-D., 2000, Management of Customer Relationship in Business Media - The Case of the Financial Industry. In: SPRAGUE, R.H., ed. Proceedings of the 33rd Hawai'i International Conference on Systems Sciences HICSS, January 4-7, Maui, Hawai'i.

KOGUT, C.A., 1990, Consumer Search Behavior and Sunk Costs. Journal of Economic Behavior \& Organization, 14, 381-392.

KOHN, M., SHAVELL, S., 1974, The Theory of Search. Journal of Economic Theory, 9: 93-123.

KULKARNI, S., 2000, The Influence of Information Technology on Information Asymmetry In Product Markets. Journal of Business and Economic Studies, 6, 55-71.

KUNDISCH, D., 2000, Buyer Search Behavior in an Electronic Commodity Market: Consumer's Decision for a Sequential or Simultaneous Search Method. In: KIM, S.H., SHENG, O., LEE, J.K., WHINSTON, A.B., SCHMID, B., eds. Proceedings of the $2^{\text {nd }}$ International Conference on Electronic Commerce 2000 (ICEC2000), Seoul, Korea, 88-93.

KUNDISCH, D., DZIENZIOL, J., EBERHARDT, M., PINNOW, M., 2001, Vergleichsmöglichkeiten für Finanzdienstleistungsangebote im WWW. Wirtschaftsinformatik, 43, 305-315.

LEE, H.G., 1998, Do electronic markets lower the price of goods? Communications of the ACM, 41, 73-80.

MCCALL, J., 1965, The economics of information and optimal stopping rules. Journal of Business, 38, $300-317$.

MONROE, K.B., 1990, Pricing: Making Profitable Decisions. New York, McGraw-Hill.

MOORTHY, S., RATCHFORD, B.T., TALUKDAR, D., 1997, Consumer Information Search Revisited: Theory and Empirical Analysis. Journal of Consumer Research, 23, 263-277.

NELSON, P., 1970, Information and consumer behavior. Journal of Political Economy, 78, 311-329.

ROTHSCHILD, M., 1975, Searching for the Lowest Price When the Distribution of Prices Is Unknown. Journal of Political Economy, 82, 689-711.

SALOP, S., STIGLITZ, J., 1977, Bargains and Rip-offs: A Model of Monopolistically Competitive Price Dispersion. Review of Economic Studies, 44, 493-510.

SALOP, S., STIGLITZ, J., 1982, The Theory of Sales: A Simple Model of Equilibrium Price Dispersion with Identical Agents. American Economic Review, 72, 1121-1130.

SCHMID, B., 1993, Elektronische Märkte, Wirtschaftsinformatik, 5, 465-480.

SHY, O., 1997, Industrial Organization, Third Printing, Cambridge, MA, MIT Press.

SKIERA, B., LAMBRECHT, A., 2000, Erlösmodelle im Internet. In: ALBERS, S., HERRMANN, A., eds. Handbuch Projektmanagement. Wiesbaden, Gabler Verlag.

SMITH, M., BAILEY, J., BRYNJOLFSSON, E., 2000, Understanding Digital Markets: Review and Assessment. In: BRYNJOLFSSON, E., KAHIN, B., eds. Understanding the Digital Economy: Data, Tools, and Research. Cambridge, MA, MIT Press, 99-136. 
STAHL, D.O., 1989, Oligopolistic Pricing with Sequential Consumer Search. The American Economic Review, 79, 700-712.

STECK, W., WILL, A., 1998, Suche im WWW: Nachfragerverhalten und Implikationen für Anbieter. In: SCHEER, A.W., NÜTTGENS, M., eds. Electronic Business Engineering - 4. Internationale Tagung Wirtschaftsinformatik 1999, Heidelberg, Physica, 289-307.

STIGLER, G., 1961, The Economics of Information. Journal of Political Economy, 69, 213-225.

STIGLITZ, J.E., 1989, Imperfect Information in the Product Market. In: SCHMALENSEE, R., WILLIG, R.D., eds. Handbook of Industrial Organization, North Holland, Elsevier Science Publishers, 769-847.

TELSER, L.G., 1973, Searching for the Lowest Price. American Economic Association, 63, 40-49.

TIROLE, J., 1988, The Theory of Industrial Organization. Cambridge, MA, MIT Press.

WEITZMAN, M.L., 1979, Optimal Search for the Best Alternative. Econometrica, 47, 641-654.

WIGAND, R., PICOT, A., REICHWALD, R., 1997, Information, Organization and Management. Chichester, John Wiley \& Sons.

WHINSTON, A., STAHL, D., CHOI, S.Y., 1997, The Economics of Electronic Commerce, Indianapolis, Macmillan Technical Publishing.

WILDE, L.L., 1980, The Economics of Consumer Information Acquisition. Journal of Business, 53, S143-S158.

WILL, A., 1997, Suchkosten und Preisdispersion auf Netzmärkten. WI-36, Diskussionspapiere des Instituts für Betriebswirtschaftslehre der Universität Augsburg.

${ }^{1}$ On electronic markets see chapter 7 in (Wigand et al. 1997) or (Schmid 1993).

${ }^{2}$ Also Koerner and Zimmermann (2000) come in their analysis of the challenges for the financial industry, let alone other things, to the conclusion that competition in the industry is increasing and that new structures and business models of the industry will evolve.

${ }^{3}$ Note that there is a significant difference in distances between suppliers and the consumer in physical markets and electronic markets. While point of sales in physical markets have quite very different distances, two online financial services providers seem to be / are level for a specific user. Physical distances will not be an issue in this contribution. Interested readers are referred to (Domschke and Drexl 1996) for warehouse location problems in physical markets. For a transfer of warehouse location problems in the virtual world see e.g. (Frank et al. 2000).

${ }^{4}$ In contrast e.g. Lee (1998) presents empirical evidence that the prices of goods traded through electronic marketplaces may be actually higher than those of products sold in traditional markets.

5 Anderson and Renault (1999) bridge the gap between the two limit cases 'Bertrand Paradox' and 'Diamond Paradox' with a sophisticated search cost model.

${ }^{6}$ Stiglitz (1989) discusses three paradoxes. The double paradox due to Diamond (1971) and the paradox that no equilibrium exists if all individuals face strict positive search costs for all searches. This paradox is due to Salop and Stiglitz (1977, 1982).

${ }^{7}$ See also (Wilde 1980), (Avery 1996).

${ }^{8}$ For excellent general overviews on search theory see e.g. (Diamond 1989) and (Stiglitz 1989). For an overview on consumer's search for information with special respect to electronic commerce and search market efficiency see chapter 7 of (Whinston et al. 1997).

${ }^{9}$ In some instances, this might be a quite realistic assumption. In the mortgage loan market, most people already know that they are looking for the least expensive standard annuity loan, hence, they already know the product the are looking for in order to finance the purchase of a house.

${ }^{10}$ This section is based on the model developed in (Kundisch 2000).

${ }^{11}$ See especially (Steck and Will 1998) for a nice graphical illustration of this fact.

${ }^{12}$ As of 09/01/2002 there were a number of ISPs in the U.S. offering free access to the Internet, such as Address.com, DotNow, Juno, and NetZero. In Germany, prices for online connections have also fallen significantly in the last years. Currently there are (regional) suppliers of flat rates (such as M'net) in the market offering access to the Internet for 
12.90 Euro/month. Call-by-call rates are well below 1Ct./minute. See e.g. http://www.preisauskunft.de or http://www.onlinekosten.de for up-to-date prices.

${ }^{13}$ Popular examples for already existing search agents include comparison shopping sites with respect to various product categories such as Dealtime (www.dealtime.com), mySimon (www.mysimon.com) PriceSCAN.com (www.pricescan.com), smartshop.com (www.smartshop.com). With regard to the financial services market popular examples in Germany include planethome (www.planethome.de; home mortgage lending), Discountbroker (www.discountbroker.de; brokerage) and einsurance (www.einsurance.de; insurance). See (Kundisch et al. 2001) for more comparison shopping sites in the financial services industry. For different examples see also (Bakos 1998).

${ }^{14}$ Thus, addressing the identified limitation of pure sequential search model by e.g. Weitzman (1979).

${ }^{15}$ A known distribution of the prices is assumed to simplify the analysis. Rothschild (1975) has shown that in many cases the qualitative characteristics of optimal search strategies with known distribution of prices are equal to those where the customer at first knows nothing about the distribution of prices but learns during her search about it. Note that the observations in a sampling process with known distribution are uninformative (cf. Telser 1973). For models with unknown distribution see e.g. (Telser 1973), (Kohn and Shavell 1974).

${ }^{16}$ The price determination process of financial services providers is not analysed; prices are taken to be given. Thus, the source of noise is exogenous.

${ }^{17}$ Thus, the model represents the static case, where the sampling takes place from a mutually independent and identically distributed population with known distribution. Any search problem not of this type is called adaptive. See e.g. (Kohn and Shavell 1974).

${ }^{18}$ See Skiera and Lambrecht (2000) for generic business models on the Internet.

${ }^{19}$ If the consumer keeps track of the financial services providers she has already visited, this probability will change as the search progresses. The probability would be $1 /(\mathrm{n}-k)$ where $k$ is the number of financial services providers already visited. For the sake of simplicity in the presented model, it is assumed that the customer does not keep track of her financial services provider visits. In fact, on the Internet, this assumption is not far from reality, since there may be different domain names all belonging to the same financial services provider. Hence, even if the consumer kept track of the already visited financial services providers she might find the same one again using a different domain.

${ }^{20}$ This relates to the reservation utility and concept of the reservation frontier if not only price but also quality features of the product or service are accounted for in the search process (cf. Nelson 1970). Kohn and Shavell (1972) call it the 'switchpoint level of utility'.

${ }^{21}$ This holds only true for $\alpha_{s e}<(2 n+1)$ which is under realistic circumstances most often the case.

${ }^{22}$ This result is already well known in literature. See e.g. Remark 7 in Kohn and Shavell (1974), Chapter 13 in De Groot (1970), Weitzman (1979), and Telser (1973). The possibility of recall is not provided for in the model presented here. In contrast to the static case, in the adaptive case keeping track of the stores visited is a superior strategy.

${ }^{23}$ It seems to reasonable to assume that a supplier knows the offers of his competitors at least as well as its customers.

${ }^{24}$ This can occur when there are only a few suppliers in the market and the search cost are relatively high. Formally if $\alpha_{s e} \geq(n-1) / 2$.

${ }^{25}$ In the case where the expected number of visits becomes analytically smaller than 1, it is assumed that the consumer searches at least once.

${ }^{26}$ Obviously, in the sequential search market, the financial services provider with the price offer equalling the reservation price will make the most profit in this market assuming identical cost functions for all suppliers. However, an analysis of the profit function in this model is fruitless since prices are taken to be given.

${ }^{27}$ Since the consumer is by assumption risk neutral (Assumption (AC)) the expected total costs of a sequential search and the certain total cost of a simultaneous search can be compared here.

${ }^{28}$ This results of this section is based on joint research efforts with Jochen Dzienziol, Michael Eberhardt, and Marian Pinnow. See (Kundisch et al. 2001).

${ }^{29}$ In fact, this was one of the basic assumptions in the search cost model. It was assumed that the customer already knew what kind of product or bundle of product she was looking for.

${ }^{30}$ Due to the relatively small sample, no tests of significance were carried out at that stage of the study.

${ }^{31}$ This table is an excerpt of the extensive results in (Kundisch et al. 2001). 
${ }^{32}$ One hint that it might still be a long way is the closedown of moneyshelf.de in November 2001 only after roughly 14 month of being online. Moneyshelf was an online marketplace established by Deutsche Bank AG to provide 'the full transparency of the financial market' (Frey 2000). After the closedown of moneyshelf.de most functionality has been integrated in the Deutsche Bank 24 website under the brand of 'Deutsche Bank 24 Moneyshop'.

${ }^{33}$ To offer a comparison function at least 2 product suppliers have to be under contract.

${ }^{34}$ The derivation of Equation (10) is analogous to Equation (1) - (7).

${ }^{35}$ Along with this hypothesis see e.g. (Brynjolfsson and Smith 2000), (Kulkarni 2000).

${ }^{36}$ See e.g. (Monroe 1990), (Moorthy et al. 1997) and references therein for research on this topic. See (Beatty and Smith 1987) and references therein for a review of empirical studies concerning buyer search effort from an involvement perspective. See (Wilde 1980) for a paper emphasizing the much needed interdisciplinary approach - integrating consumer research and economic models - concerning consumer search behaviour. Moreover, an empirical study due to Kogut (1990) provides evidence that simple marginal search theory, i.e. reservation price strategy, does not adequately predict individual behaviour. 